\title{
ST-Segment Elevation in the Right Precordial Leads in Patients with Acute Anterior Myocardial Infarction
}

\author{
Leili Pourafkari $^{1}$, Saeid Joudi ${ }^{1}$, Samad Ghaffari ${ }^{1}$, Arezou Tajlil ${ }^{1}$, Babak Kazemi ${ }^{1}$, Nader D. Nader ${ }^{2}$
}

${ }^{1}$ Department of Cardiology, Tabriz University of Medical Sciences Cardiovascular Research Center, Tabriz, Iran
${ }^{2}$ Department of Anesthesiology, University at Buffalo Jacobs School of Medicine and Biomedical Sciences, New York, USA

Background: Elevation of ST segment in leads V3R/ $\mathrm{V} 4 \mathrm{R}$, which is commonly encountered in right ventricular myocardial infarction, may also occur in patients with anterior ST elevation myocardial infarction (STEMI). However, the clinical impact of this finding in the setting of anterior myocardial infarction is not well understood. Aims: We aimed to investigate the prognostic value of ST segment elevation in leads V3R/V4R in patients with first acute anterior myocardial infarction.

Study Design: Prospective cohort study.

Methods: Right precordial leads V3R/V4R were recorded in 111 patients admitted with first time anterior myocardial infarction. Patients were allocated into two groups based on the presence or absence of ST elevation in leads V3R/V4R. Demographic, biochemical and echocardiographic data, as well as the angiographic information, were recorded. In-hospital and 3 month mortality, and major adverse cardiac events (MACE), death, heart failure and ventricular dysrhythmia were also compared.

Results: ST elevation in lead V3R or V4R was present in 72 out of 111 patients $(64.9 \%)$. Involvement of the proximal part of the left anterior descending (LAD) artery was not different in the two groups ( $44.4 \%$ of patients with elevation vs. $53.8 \%$ of patients without elevation, $\mathrm{p}=0.22$ ). Post-myocardial infarction complications, mortality and major adverse cardiac events were similar in the two groups. Left ventricular ejection fraction (LVEF) was significantly lower in patients with ST elevation in V3R/V4R ( $35 \% \pm 8$ vs. $38 \% \pm 8, \mathrm{p}=0.02)$. Twenty three out of 111 patients (20.7\%) developed heart failure, which was similar in the two groups [16 $(22.2 \%)$ of patients with ST elevation vs. 7 (17.9\%) of patients without ST elevation, $\mathrm{p}=0.39$ ].

Conclusion: Although ST elevation in V3R/V4R can be present in patients with left anterior descending artery occlusion, it does not seem to predict the prognosis. Lower left ventricular ejection fraction in this group may play a role in the long-term prognosis; however, this issue needs further investigation.

Keywords: Acute anterior myocardial infarction, electrocardiograph, right ventricular dysfunction
Identifying the location of the culprit coronary lesion in patients with acute myocardial infarction (MI) may help clinicians to estimate a patient's prognosis and decide on the best therapeutic approach $(1,2)$. Anterior wall MI, which accounts for the highest MI mortality compared with other regions, is commonly associated with left anterior descending (LAD) artery occlusion (3). Electrocardiography (ECG), which is a noninvasive and fast method to evaluate patients with suspected coronary disease, may provide valuable information about the location of occlusion in LAD artery. Most studies, which have suggested predictive ECG patterns, however, have not included the leads V3R and V4R in their evaluations (4-6).

Address for Correspondence: Dr. Samad Ghaffari, Department of Cardiology, Tabriz University of Medical Sciences Cardiovascular Research Center, Tabriz, Iran Phone: 00989143137973 e-mail: ghafaris@gmail.com

Received: 27.11.2014 Accepted: $15.06 .2015 \cdot$ DOI: 10.5152/balkanmedj.2015.15975

Available at www.balkanmedicaljournal.org

Pourafkari L, Joudi S, Ghaffari S, Tajlil A, Kazemi B, Nader ND. ST-Segment elevation in the right precordial leads in patients with acute anterior myocardial infarction. Balkan Med J 2016;33:58-63 
The ST segment elevation (STE) in leads V3R and V4R is commonly encountered in right ventricular myocardial infarction (RVMI), a condition that is rarely diagnosed as an isolated problem (7). Although right precordial leads are not routinely recorded as a part of standard 12-lead ECG, they are a crucial part of electrocardiographic evaluations in patients with inferior myocardial infarction (8-10). Inferior and posterior parts of the left ventricle as well as the posterior regions of the right ventricle are all supplied by the right coronary artery (RCA) in the majority of cases. Consequently, RVMI often occurs in conjunction with inferior MI (2). It has also been well established that concurrent RVMI increases in-hospital complications and mortality rate in patients with inferior MI (10).

ST elevation in leads V3R and V4R is also described as an occasional finding in some patients with anterior ST elevation myocardial infarction (STEMI); however, the way in which it influences the prognosis of patients is a matter of controversy (10-15). The fact that the LAD artery supplies anterior regions of the right ventricle could explain the occurrence of RVMI following LAD occlusion (16), but the possible location of stenosis in LAD artery is not well understood (12).

Regarding these facts, we conducted a prospective study on patients with anterior STEMI to investigate the possible role of ST elevation in leads V3R and V4R in predicting the angiographic site of stenosis in the LAD artery. In addition, we examined the effect of simultaneous RVMI with anterior MI on the occurrence of in-hospital complications as well as the incidence of congestive heart failure (HF) and mortality.

\section{MATERIALS AND METHODS}

This prospective cohort study included one hundred and eleven consecutive patients, who were admitted to our cardiovascular heart center between March 2012 and September 2013, with a first anterior STEMI. Patients who had ECG evidence or history of myocardial infarction, bundle branch blocks or pacemaker implantation were excluded from the study.

All of the included patients presented to the hospital within 12 hours of the onset of chest pain. Along with standard 12lead ECG, V3R and V4R leads were also recorded on admission using a paper speed of $25 \mathrm{~mm} / \mathrm{s}$ and standardization of $1 \mathrm{mV} / 10 \mathrm{~mm}$. The presence of ST elevation in these leads was investigated manually. Based on current therapeutic guidelines, patients either underwent primary percutaneous coronary intervention (PCI) or received thrombolytic therapy and PCI was scheduled for the following days.

Acute anterior STEMI was defined as more than 30 minutes typical chest pain with ST elevation of more than $0.2 \mathrm{mV}$ from the $\mathrm{J}$ point in at least in two consecutive precordial leads on the admission ECG and also an increase in cardiac enzymes, which was defined as an increase of one point above the 99th percentile cut off point for MB isoenzyme of creatine kinase (CK-MB) and Cardiac-Troponin I (cTNI). ST elevation in V3R and V4R leads was defined as more than or equal to 0.1 $\mathrm{mV}$ ST elevation from the J point on the admission ECG. Heart failure was defined as having pulmonary rales on auscultation, signs of congestion in Chest X-Ray and any need for diuretic administration. At least $50 \%$ reduction of the luminal diameter of the coronary artery was considered significant stenosis.

The patients were categorized into two groups based on the presence or absence of ST elevation in either the V3R or V4R lead. The comprehensive demographic, clinical and biochemical data were recorded in both groups. All patients underwent echocardiographic evaluation in the first 24 hours following admission. Information about the occurrence of ventricular fibrillation (VF), ventricular tachycardia (VT), nodal or bundle branch blocks, other arrhythmias, pericardial effusion and congestive heart failure was collected during hospitalization. All patients were followed by phone call three to six months after their first hospital admission. Patients' mortality during hospitalization and follow-up period was recorded. Major cardiovascular adverse events (MACE) were defined as death, heart failure or ventricular dysrhythmias.

Based on the angiographic reports, the location of stenosis in LAD artery and also the presence of any significant stenosis in left circumflex (LCX) and right coronary artery were recorded in every patient. The location of stenosis in the LAD artery was classified into two groups. The lesions from the origin of LAD to the first septal or diagonal branch were defined as proximal and the lesions distal to the first septal or diagonal branch were defined as non-proximal. MACE was compared in patients with and without ST elevation in V3R/V4R.

The study was reviewed and approved by the Institutional Review Board Committee of our university and exempted from informed consent due to its descriptive design. However, complete patient privacy was maintained.

\section{Statistical analysis}

Statistical software SPSS (PASW Statistics for Windows, Version 18.0, SPSS Inc.; Chicago, IL, USA) was used for data analysis. Continuous variables were presented as the mean \pm standard deviation and categorical variables were reported as frequencies and percentages. Fisher's exact test or Chi-square analysis was done as appropriate to compare the frequencies of categorical variables. The independent t-test was used to compare the numerical variables between two study groups. A p value of less than 0.05 was considered statistically significant. 


\section{RESULTS}

A total of 111 patients with anterior STEMI were studied. The mean age of patients was $60 \pm 11$ years. Overall, 91 out of 111 patients $(82 \%)$ were male and the remaining 20 patients $(18 \%)$ were female. The mean time interval between the onset of chest pain and recording of the first ECG was $5.7 \pm 0.8$ hours. The electrocardiographic location of infarction was anterolateral in 46 patients (41.4\%), anteroseptal in 41 patients (36.9\%), and extensive anterior in 24 patients $(21.6 \%)$. The mean ST elevation in the study population was $0.94 \pm 0.83 \mathrm{mV}$ in lead V3R and $0.47 \pm 0.05 \mathrm{mV}$ in lead V4R. The mean ST elevation sum in all leads was $14.4 \pm 9.4 \mathrm{mV}$.

The patients were allocated into two groups based on the presence or absence of ST elevation (STE) in either lead V3R or V4R. Seventy-two out of 111 patients $(64.9 \%)$ had ST elevation in lead V3R or V4R and 39 patients (35.1\%) did not. There were no differences between the two groups regarding mean age, sex and coronary artery disease risk factors, with the exception of diabetes, which was significantly more prevalent in patients without STE in leads V3R/V4R (41\% vs. $19.4 \%, \mathrm{p}=0.02$ ).

Cardiac enzyme biomarkers as well as serum lipid levels were similar in the two groups. Mean peak CK-MB was $231 \pm 261 \mathrm{ng} / \mathrm{mL}$ in the group without STE and it was $188 \pm 156$ $\mathrm{ng} / \mathrm{mL}$ in the other group $(\mathrm{p}=0.39)$. Peak cTNI was $16.7 \pm 15.9$ $\mathrm{ng} / \mathrm{mL}$ in the group without STE and $18.7 \pm 13.8 \mathrm{ng} / \mathrm{mL}$ in the group with STE $(\mathrm{p}=0.369)$. The admission blood sugar level was higher in the group without STE $(188 \pm 104 \mathrm{mg} / \mathrm{dL}$ vs. $154 \pm 72 \mathrm{mg} / \mathrm{dL}, \mathrm{p}=0.047$ ) (Table 1).

The occurrence of VF/VT on the first day of hospitalization was not different between the two groups $(5.6 \%$ in the group with STE vs. $5.1 \%$ in the group without STE, $\mathrm{p}=0.9$ ), so was on other days. Atrioventricular (AV) node blocks, right bundle branch block (RBBB) and paroxysmal supraventricular tachycardia (PSVT) did not occur in any patient.

Sixteen out of 72 patients (22.2\%) with STE in V3R/V4R developed heart failure; in contrast, seven out of 39 patients $(17.9 \%)$ without STE in V3R/V4R developed heart failure. However, this difference was not statistically significant $(p=0.4)$. Based on the echocardiographic data, in patients with STE in V3R/V4R, left ventricular ejection fraction (LVEF) was significantly lower than the other group ( $35 \pm 8 \%$ vs. $39 \pm 8 \%$, $\mathrm{p}=0.022)$. Severe mitral regurgitation $(\mathrm{MR}>2+)$ was present in 9 patients (12.5\%) in the group with STE compared with one patient $(2.6 \%)$ in the other group $(\mathrm{p}=0.07)$. Right ventricular ejection fraction (RVEF) and right ventricular size were reported to be normal in echocardiographic evaluations of all patients.

The mean hospital stay was $6.6 \pm 4.4$ days for patients with STE and it was 7.0 \pm 3.9 days for patients without STE $(\mathrm{p}=0.57)$. The mortality of patients including follow-up period mortality was 6 out of the 111 studied cases (5.4\%). The inhospital mortality was similar between the two groups, as was the mortality rate in the follow-up period. Table 1 summarizes demographic data, risk factors, biochemical data, complications, mortality, angiographic findings and location of the culprit coronary artery in patients with and without ST Elevation in Leads V3R/V4R.

The occurrence of HF/shock in patients with STE in V3R, V4R and V3R or V4R was not significantly different. STE in V3R was reported in $17(68 \%)$ patients with MACE and STE in V4R was present in $11(44.0 \%)$ patients with MACE (Table 2).

Reviewing the angiographic reports revealed the presence of one-vessel disease in 49 out of 111 patients (44.1\%). LAD artery stenosis was present in all of the patients. The stenosis was due to proximal lesion in 53 out of 111 patients (47.7\%) and non-proximal lesion in 58 out of 111 patients $(52.3 \%)$. Along with LAD artery stenosis, in 62 out of 111 patients (55.9\%), either the RCA or LCX artery was also involved. Stenosis of both RCA and LCX was present in 25 out of 111 patients $(22.5 \%)$. Twenty out 111 patients $(18 \%)$ had RCA lesions and 17 out of 111 (15.3\%) had LCX lesions. Chronic total occlusion of RCA was seen in $5(4.5 \%)$ patients.

No significant association was found between the presence of ST elevation in leads V3R, V4R and the location of LAD occlusion in relation to the origin of the first diagonal or septal branch.

STE in V3R was present in 32 cases (60.4\%) in the group with proximal LAD involvement. STE in V4R was present in 17 cases $(32.1 \%)$ of the group with Proximal LAD involvement, and 32 patients $(60.4 \%)$ with proximal LAD involvement had STE in lead V3R or V4R. The sum of STE in all leads was also not significantly different between those with proximal vs. non-proximal LAD lesions (Table 3).

\section{DISCUSSION}

This study suggests that ST elevation in leads V3R/V4R, as the representative of right ventricular ischemia, is not related to the location of stenosis in the LAD artery. Concurrent RV infarction and anterior STEMI may occur in both proximal and distal LAD occlusions. Prior studies have explained some ECG patterns in patients with anterior STEMI that predict the location of LAD occlusion $(5,6,17)$. However, with regard to our findings, this is not true for leads V3R/ V4R. Similarly, in a previous study, Barsheshet et al. (12) investigated the association of proximal LAD involvement and concurrent anterior and RV MI and found no difference 
TABLE 1. Comparison of demographic, biochemical, echocardiographic and angiographic data in patients regarding the absence or presence of ST elevation in leads V3R, V4R, V3R or V4R

\begin{tabular}{|c|c|c|c|c|c|}
\hline & $\begin{array}{c}\text { V3R STE } \geq 1 \\
(\mathrm{~N}=70)\end{array}$ & $\begin{array}{c}\text { V4R STE } \geq 1 \\
(\mathrm{~N}=42)\end{array}$ & $\begin{array}{c}V 3-4 R \geq 1 \\
(N=72)\end{array}$ & $\begin{array}{l}\text { No STE } \\
(\mathrm{N}=39)\end{array}$ & $\mathrm{p}$ \\
\hline Age (years) & $61 \pm 12$ & $63 \pm 12$ & $61 \pm 12$ & $59 \pm 10$ & 0.386 \\
\hline Male sex & $55(78.6 \%)$ & $32(76.2 \%)$ & $57(79.2 \%)$ & $34(87.2 \%)$ & 0.217 \\
\hline Hypertension & $33(47.1 \%)$ & $21(50 \%)$ & $33(45.8 \%)$ & $13(33.3 \%)$ & 0.141 \\
\hline Diabetes Mellitus & $14(20 \%)$ & $9(21.4 \%)$ & $14(19.4 \%)$ & $16(41.0 \%)$ & 0.024 \\
\hline Active Smoking & $26(37.1 \%)$ & $14(33.3 \%)$ & $27(37.5 \%)$ & $12(30.8 \%)$ & 0.536 \\
\hline Hyperlipidemia & $4(5.7 \%)$ & $3(7.1 \%)$ & $4(5.6 \%)$ & $5(12.8 \%)$ & 0.164 \\
\hline Creatinine (mg/dL) & $1.0 \pm 0.3$ & $1.0 \pm 0.3$ & $1.0 \pm 0.3$ & $1.1 \pm 0.3$ & 0.062 \\
\hline Triglyceride (mg/dL) & $141 \pm 94$ & $158 \pm 111$ & $139 \pm 94$ & $132 \pm 66$ & 0.617 \\
\hline Cholesterol (mg/dL) & $191 \pm 54$ & $193 \pm 41$ & $190 \pm 54$ & $184 \pm 41$ & 0.500 \\
\hline Hematocrit (percent) & $42.9 \pm 5.6$ & $41.9 \pm 5.3$ & $42.9 \pm 5.6$ & $41.0 \pm 6.0$ & 0.123 \\
\hline Peak Creatine Kinase (MB) & $191 \pm 157$ & $155 \pm 142$ & $188 \pm 156$ & $231 \pm 261$ & 0.369 \\
\hline Creatine Kinase (MB) D1 & $81 \pm 101$ & $55 \pm 53$ & $81 \pm 100$ & $88 \pm 128$ & 0.749 \\
\hline Creatine Kinase (MB) D2 & $147 \pm 138$ & $137 \pm 149$ & $144 \pm 137$ & $187 \pm 268$ & 0.356 \\
\hline Peak cTNI (ng/mL) & $18.6 \pm 13.9$ & $18.2 \pm 13.3$ & $18.7 \pm 13.8$ & $16.7 \pm 15.9$ & 0.369 \\
\hline cTNI (ng/mL) D1 & $10.9 \pm 15.8$ & $11.3 \pm 16.6$ & $11.1 \pm 15.6$ & $5.7 \pm 11.4$ & 0.037 \\
\hline $\mathrm{cTNI}(\mathrm{ng} / \mathrm{mL}) \mathrm{D} 2$ & $13.4 \pm 10.4$ & $12.1 \pm 10.1$ & $13.4 \pm 10.3$ & $22.5 \pm 53.5$ & 0.299 \\
\hline Ventricular Dysrhythmias E & $2(2.9 \%)$ & $1(2.4 \%)$ & $2(2.8 \%)$ & $0(0.0 \%)$ & 0.419 \\
\hline Ventricular Dysrhythmias L & $4(5.7 \%)$ & $1(2.4 \%)$ & $4(5.6 \%)$ & $2(5.1 \%)$ & 0.647 \\
\hline Acute Heart failure & $16(22.9 \%)$ & $11(26.2 \%)$ & $16(22.2 \%)$ & $7(17.9 \%)$ & 0.393 \\
\hline LV Ejection Fraction (\%) & $35 \pm 8$ & $35 \pm 8$ & $35 \pm 8$ & $39 \pm 8$ & 0.022 \\
\hline Proximal LAD lesion & $32(45.7 \%)$ & $17(40.5 \%)$ & $32(44.4 \%)$ & $21(53.8 \%)$ & 0.227 \\
\hline Hospital stay & $6.5 \pm 4.4$ & $7.3 \pm 5.4$ & $6.6 \pm 4.4$ & $7.0 \pm 3.9$ & 0.561 \\
\hline In-hospital Death & $2(2.9 \%)$ & $2(4.8 \%)$ & $2(2.8 \%)$ & $4(10.3 \%)$ & 0.113 \\
\hline MACE & $17(24.3 \%)$ & $11(26.2 \%)$ & $17(23.6 \%)$ & $8(20.5 \%)$ & 0.452 \\
\hline Mitral Regurgitation $>2+$ & $9(12.9 \%)$ & $4(9.5 \%)$ & $9(12.5 \%)$ & $1(2.6 \%)$ & 0.075 \\
\hline $1 \mathrm{VD} / 2 \mathrm{VD} / 3 \mathrm{VD}$ & $27 / 26 / 17$ & $13 / 13 / 16$ & $28 / 26 / 18$ & $21 / 9 / 9$ & 0.291 \\
\hline Thrombolytic therapy & $53(75.7 \%)$ & $37(88.1 \%)$ & $55(76.4 \%)$ & $26(66.7 \%)$ & 0.190 \\
\hline Primary PCI & $12(17.1 \%)$ & $4(9.5 \%)$ & $12(16.7 \%)$ & $10(25.6 \%)$ & 0.320 \\
\hline PCI beyond first day & $32(45.7 \%)$ & $17(40.5 \%)$ & $33(45.8 \%)$ & $20(51.3 \%)$ & 0.691 \\
\hline Sum of all STE & $15.1 \pm 10.8$ & $13.7 \pm 10.2$ & $14.8 \pm 10.8$ & $13.4 \pm 6.1$ & 0.382 \\
\hline
\end{tabular}

STE: ST elevation; cTNI: cardiac troponin I; E: early; L: late; LV: left ventricle; LAD: left anterior descending; 1VD: one vessel disease; 2VD: two vessel disease; 3VD: three vessel disease; PCI: percutaneous coronary intervention; D1: admission time; D2: 12 hours later; MACE: Major Cardiac Adverse Events

${ }^{*} \mathrm{p}<0.05$ is statistically significant.

Continuous variables are mean $\pm \mathrm{SD}$ and categorical variables are number of cases (percentages).

TABLE 2. Frequency of clinical endpoints in patients with ST elevation in V3R, V4R, V3R or V4R

\begin{tabular}{lcccccc}
\hline & $\begin{array}{c}\text { HF/shock } \\
(\mathrm{N}=23)\end{array}$ & $\begin{array}{c}\text { No HF } \\
(\mathrm{N}=88)\end{array}$ & $\mathrm{p}$ & $\begin{array}{c}\text { MACE } \\
(\mathrm{N}=25)\end{array}$ & $\begin{array}{c}\text { No MACE } \\
(\mathrm{N}=86)\end{array}$ & $\mathrm{p}$ \\
\hline V3R STE & $16(69.6 \%)$ & $54(61.4 \%)$ & 0.318 & $17(68.0 \%)$ & $53(61.6 \%)$ & 0.369 \\
V4R STE & $11(47.8 \%)$ & $31(35.2 \%)$ & 0.192 & $11(44.0 \%)$ & $31(36.0 \%)$ & 0.310 \\
V3R or V4 & $16(69.6 \%)$ & $56(63.6 \%)$ & 0.636 & $17(68.0 \%)$ & $55(64.0 \%)$ & 0.452 \\
All leads STE (Millimeter) & $15.1 \pm 8.7$ & $14.2 \pm 9.6$ & 0.656 & $16.4 \pm 10.8$ & $13.8 \pm 8.9$ & 0.280 \\
\hline
\end{tabular}

STE: ST elevation; HF: heart failure; MACE; Major Cardiac Adverse Events $* \mathrm{p}<0.05$ is statistically significant. 
TABLE 3. Frequency of ST elevation in leads V3R, V4R, V3R or V4R in patients with and those without proximal lesion of left anterior descending artery

\begin{tabular}{lccc}
\hline & $\begin{array}{c}\text { Proximal LAD } \\
\text { lesion }(\mathrm{n}=53)\end{array}$ & $\begin{array}{c}\text { Non-Proximal } \\
\text { LAD lesion }(\mathrm{n}=58)\end{array}$ & $\mathrm{p}$ \\
\hline V3R STE & $32(60.4 \%)$ & $38(65.5 \%)$ & 0.694 \\
V4R STE & $17(32.1 \%)$ & $25(43.1 \%)$ & 0.247 \\
V3R or V4 & $32(60.4 \%)$ & $40(69.0 \%)$ & 0.427 \\
All leads STE (millimeter) & $14.5 \pm 8.7$ & $14.2 \pm 10.0$ & 0.885 \\
\hline STE: ST elevation; LAD: left anterior descending & & \\
*p $<0.05$ is statistically significant. & &
\end{tabular}

between two groups of patients with and without ST elevation in right precordial leads.

As right precordial leads provide valuable prognostic information in patients with inferior MI, they are often recorded in this patient group (18). The STE in V4R is suggested as a strong independent predictor of complications and mortality in patients with inferior MI (10), but its value in predicting the prognosis of patients with anterior STEMI has not been well studied and the data are limited. However, following the studies demonstrating a relatively high incidence of this condition, there is increasing interest in the literature about the consequences of RV MI $(12,13,15)$. As reported in this study, concurrent right precordial ST elevation and anterior STEMI is not a rare finding and was present in $64.9 \%$ of our patients with anterior MI. However, further investigations regarding $\mathrm{RV}$ dysfunction and RV ejection fraction (RVEF) showed that none of the patients had developed RV dysfunction, and RVEF was also normal in all patients. This finding could be explained with regard to high RV salvage after reperfusion therapy.

In a recent study, Bodi et al. (13) investigated the effect of proximal LAD stenosis on RV and LV myocardium, and proved that stenosis in the LAD artery may also predispose a large area of the anterior wall of the RV to ischemia, but the resultant infarct size would be small. Similar to our results, Barsheshet et al. (12) reported normal RV function in their studied patients. However, in another study, Tahirkheli et al. (15) evaluated autopsy specimens of 88 cases with anteroseptal MI, and found eight cases with concurrent RV MI, in some of whom RV hemodynamic changes in retrospective angiographic results had been reported; however, due to the small number of patients with RV MI in the study sample, their results may not apply to all patients.

In the present study, the development of acute left heart failure following acute MI was similar in either group. In addition, in-hospital mortality rate as well as the mortality rate in the follow-up period was not different in patients with and those without ST elevation in leads V3R/V4R. Anterior LVMI is suggested as a predictor for developing heart failure in patients with MI and larger infarct size following LAD artery oc- clusion is described as a causative factor $(19,20)$. On the other hand, RV ischemia with concurrent anterior MI may only result in a small RV infarct size (13). This may be a possible description for our findings regarding the same rate of heart failure and mortality in both groups. Moreover, in the paper published by Bodi et al. (13), similar rates of heart failure were reported for both groups of patients. This is in contrast to the findings of the study by Barsheshet et al. (12), in which patients with ST elevation in leads V3R/V4R had a higher rate of heart failure, mortality and development of VF in comparison to those with only anterior LV MI. In their study sample, patients with prior history of coronary disease were not excluded; however, their two study groups were similar regarding this factor. Furthermore, the low incidence of these endpoints, especially with regard to VF, may be problematic for interpretation of their data. In this study, we excluded patients with a history of coronary disease to eliminate the effects of any possible prior injury to the myocardium, and found no association between STE in V3R/V4R and the development of VF. However, the incidence of VF was low in our patients, as described for the later study.

According to the results, LVEF was slightly lower in patients with STE in leads V3R/V4R. Considering the similarity of the two groups regarding the development of heart failure, this finding may not have significant clinical importance in practice. Also, there was a trend towards a higher rate of significant MR in patients with STE in leads V3R/V4R. Barsheshet et al. (12) reported an abnormality of middle anteroseptal wall motion, detected by echocardiographic evaluations, in patients with concurrent STE in V4R. This synchrony may describe the higher rate of significant MR in our patients, which needs to be confirmed in future large studies. In contrast to our study, in the latter study, LVEF was similar in both groups. There are some reports regarding the protective role of the conus branch of the right coronary artery on interventricular septum and STE of V1 or right precordial leads (21). Anatomical variations of this branch may be an important confounding factor leading to different results regarding the frequency of arrhythmias, heart failure and LVEF in various studies.

We conclude that ST elevation in leads V3R/V4R is not a rare finding in patients with anterior STEMI; however, it does not change the prognosis of patients with anterior MI. Despite normal RV function, LVEF is slightly lower in this group of patients.

Furthermore, STE in leads V3R/V4R does not predict the location of stenosis in the LAD artery. However, this study investigated a relatively small number of real-life patients without any additional diagnostic or therapeutic interventions. Further studies with a larger number of patients are needed to evaluate this association. 
Ethics Committee Approval: Ethics committee approval was received for this study from the ethics committee of Tabriz University of Medical Sciences.

Informed Consent: Written informed consent was obtained from patients who participated in this study.

Peer-review: Externally peer-reviewed.

Author contributions: Concept - L.P., S.J., S.G., B.K.; Design S.G., B.K., N.N., A.T.; Supervision - S.G., L.P., N.N., B.K.; Resource - S.G., B.K., L.P.; Materials - L.P., S.G., S.J., A.T., B.K.; Data Collection \&/or Processing - S.G., L.P., S.J., A.T., B.K., N.N.; Analysis \&/ or Interpretation - A.T., N.N., L.P., S.G.; Literature Search - L.P., S.J., S.G., A.T., B.K., N.N.; Writing - L.P., S.J., S.G., A.T., B.K., N.N.; Critical Reviews - L.P., S.G., N.N.

Conflict of Interest: No conflict of interest was declared by the authors.

Financial Disclosure: The authors declared that this study has received no financial support.

\section{REFERENCES}

1. Yip HK, Chen MC, Wu CJ, Chang HW, Yu TH, Yeh KH, et al. Acute myocardial infarction with simultaneous ST-segment elevation in the precordial and inferior leads: evaluation of anatomic lesions and clinical implications. Chest 2003;123:117080. [CrossRef]

2. Zimetbaum PJ, Josephson ME. Use of the Electrocardiogram in Acute Myocardial Infarction. N Eng J Med 2003;348:933-40. [CrossRef]

3. Elsman P, van 't Hof AWJ, Hoorntje JCA, de Boer M-J, Borm GF, Suryapranata H, et al. Effect of Coronary Occlusion Site on Angiographic and Clinical Outcome in Acute Myocardial Infarction Patients Treated With Early Coronary Intervention. Am J Cardiol 2006;97:1137-41. [CrossRef]

4. Eskola MJ, Nikus KC, Holmvang L, Sclarovsky S, Tilsted HH, Huhtala $\mathrm{H}$, et al. Value of the 12-lead electrocardiogram to define the level of obstruction in acute anterior wall myocardial infarction: Correlation to coronary angiography and clinical outcome in the DANAMI-2 trial. Int J Cardiol 2009;131:378-83. [CrossRef]

5. Engelen DJ, Gorgels AP, Cheriex EC, De Muinck ED, Oude Ophuis AJ, Dassen WR, et al. Value of the electrocardiogram in localizing the occlusion site in the left anterior descending coronary artery in acute anterior myocardial infarction. $J \mathrm{Am} \mathrm{Col}$ Cardiol 1999;34:389-95. [CrossRef]

6. Noriega FJ, Vives-Borrás M, Solé-González E, García-Picart J, Arzamendi D, Cinca J. Influence of the Extent of Coronary Atherosclerotic Disease on ST-Segment Changes Induced by ST Elevation Myocardial Infarction. Am J Cardiol 2014;113:75764. [CrossRef]

7. Logeart D, Himbert D, Cohen-Solal A. St-segment elevation in precordial leads* : Anterior or right ventricular myocardial infarction? Chest 2001;119:290-2. [CrossRef]
8. Inohara T, Kohsaka S, Fukuda K, Menon V. The challenges in the management of right ventricular infarction. Eur Heart $J$ Acute Cardiovasc Care 2013;2:226-34. [CrossRef]

9. Ondrus T, Kanovsky J, Novotny T, Andrsova I, Spinar J, Kala P. Right ventricular myocardial infarction: From pathophysiology to prognosis. Exp Clin Cardiol 2013;18:27-30.

10. Zalenski RJ, Rydman RJ, Sloan EP, Hahn K, Cooke D, Tucker $\mathrm{J}$, et al. ST segment elevation and the prediction of hospital lifethreatening complications: the role of right ventricular and posterior leads. J Electrocardiol 1998;(Suppl 31):164-71. [CrossRef]

11. Walker LA, Buttrick PM. The right ventricle: biologic insights and response to disease: updated. Cur Cardiol Rev 2013;9:7381. [CrossRef]

12. Barsheshet A, Hod H, Oieru D, Goldenberg I, Sandach A, Beigel $\mathrm{R}$, et al. Right precordial lead (V4R) ST-segment elevation is associated with worse prognosis in patients with acute anterior myocardial infarction. J Am Coll Cardiol 2011;58:548-9. [CrossRef]

13. Bodi V, Sanchis J, Mainar L, Chorro FJ, Nunez J, Monmeneu JV, et al. Right ventricular involvement in anterior myocardial infarction: a translational approach. Cardiovasc Res 2010;87:6018. [CrossRef]

14. Zhong-qun Z, Wei W, Chong-quan W, Shu-yi D, Chao-rong $\mathrm{H}$, Jun-feng W. Acute anterior wall myocardial infarction entailing ST-segment elevation in lead V3R, V1 or a VR: electrocardiographic and angiographic correlations. J Electrocardiol 2008;41:329-34. [CrossRef]

15. Tahirkheli NK, Edwards WD, Nishimura RA, Holmes DR, Jr. Right ventricular infarction associated with anteroseptal myocardial infarction: a clinicopathologic study of nine cases. Cardiovasc Path 2000;9:175-9. [CrossRef]

16. Haddad F, Doyle R, Murphy DJ, Hunt SA. Right Ventricular Function in Cardiovascular Disease, Part II: Pathophysiology, Clinical Importance, and Management of Right Ventricular Failure. Circulation 2008;117:1717-31. [CrossRef]

17. Meissner A, Trappe HJ, de Boer MJ, Gorgels AP, Wellens HJ. The value of the ECG for decision-making at first medical contact in the patient with acute chest pain. Neth Heart $J$ 2010;18:301-6. [CrossRef]

18. O'Rourke RA, Dell'Italia LJ. Diagnosis and management of right ventricular myocardial infarction. Curr Probl Cardiol 2004;29:6-47. [CrossRef]

19. Stebbins A, Mehta RH, Armstrong PW, Lee KL, Hamm C, Van de Werf F, et al; Assessment of Pexelizumab in Acute Myocardial Infarction (APEX AMI Investigators). A Model for Predicting Mortality in Acute ST-Segment Elevation Myocardial Infarction Treated With Primary Percutaneous Coronary Intervention: Results From the Assessment of Pexelizumab in Acute Myocardial Infarction Trial. Circ Cardiovasc Interv 2010;3:414-22. [CrossRef]

20. Masci PG, Ganame J, Francone M, Desmet W, Lorenzoni V, Iacucci I, et al. Relationship between location and size of myocardial infarction and their reciprocal influences on post-infarction left ventricular remodelling. Eur Heart J 2011;32:1640-8. [CrossRef]

21. Ben-Gal T, Sclarovsky S, Herz I, Strasberg B, Zlotikamien B, Sulkes J, et al. Importance of the conal branch of the right coronary artery in patients with acute anterior wall myocardial infarction: electrocardiographic and angiographic correlation. $J$ Am Coll Cardiol 1997;29:506-11. [CrossRef] 